\title{
DIREITOS HUMANOS E MEIO AMBIENTE DO TRABALHO DA MULHER: REFLEXÕES ACERCA DO PRINCÍPIO DA IGUALDADE
}

\section{HUMAN RIGHTS AND THE ENVIRONMENT OF WOMEN'S WORK: REFLECTIONS ON THE PRINCIPLES OF EQUALITY}

Resumo: Trata-se de uma análise da problemática da desigualdade em razão do gênero sob o enfoque da divisão sexual do trabalho, a partir do levantamento histórico do surgimento do movimento feminista, e da concretização do princípio da igualdade nos Estados Unidos da América (EUA). Analisa a relação de trabalho e outras formas de reprodução social que perpetuam as relações de gênero, e explicita a extensão da segregação ocupacional e da segregação das tarefas no processo do trabalho. Para uma melhor compreensão e localização do tema no tempo e no espaço,utilizou-se de metodologia bibliográfico-documental, em que são estudados o surgimento do movimento feminista no Brasil e suas configurações, bem como aspectos da divisão sexual do trabalho, como a divisão e precariedade do trabalho feminino e constata a necessidade de políticas de educação para efetivação da sustentabilidade.

Palavras-chave: Igualdade. Democracia. Trabalho. Educação. Sustentabilidade.

Abstract: This is an analysis of the problem of inequality on grounds of gender under the focus of sexual division of labor, from the historic survey of the rise of the feminist movement, and the implementation of the principle of equality in the United States of America (USA). Analyzes the employment relationship and other forms of social reproduction that perpetuate gender relations and explains the extent of occupational segregation and segregation of tasks in the process of work. For a better understanding and theme location in time and space are studied the emergence of the feminist movement in Brazil and their settings, as well as aspects of the sexual division of labor, as the division and precariousness of female employment and notes the need for policies effective sustainability education.

Keywords: Equality. Democracy. Work. Education. Sustainability.

\footnotetext{
"Mestranda em Meio Ambiente e Desenvolvimento Regional e Sustentabilidade pela UNIDERP. Atua como defensora - Justiça Federal da $3^{\text {a }}$ Região.
} 


\section{NOTAS INICIAIS}

A sociedade brasileira exerce a discriminação de gênero como forma de reprodução social, explicitando as relações de gênero em discriminação,aqual está imbricada em referencial cultural, fundamentado na desigualdade entre homens e mulheres. A violência contra as mulheres integra a cultura de nossa sociedade, e ainda é vista como resultado da conduta feminina inadequada, e suficientemente capaz de justifica-la socialmente.

A discriminação de gênero está estabelecida na sociedade brasileira desde o berço, sendo praticada, inclusive, por mulheres, e com papéis sociais muito bem delimitados, em que o espaço público se destina aos homens e o espaço privado às mulheres.

Há um paradoxo quando apontamos toda a estrutura de direitos adquiridos disponibilizados a partir da promulgação da Constituição Federal vigente. Houve um trabalho desenvolvido para a ampliação recente de direitos que culminou na promulgação do Código Civil/2002, consubstancia que o feminismo de primeira geração surgido no século XVIII, e segunda geração, entre as décadas de 19601980, foram superados, estabelecendo que o movimento está mais inclinado a trabalhar com o patriarcado, no lugar de lutar contra ele.

A Carta Constitucional de 1988 foi instrumento fundamental para criar e consolidar a igualdade de gênero. Entretanto, sua efetividade é realidade distante. Intitulada "Constituição Cidadã", a igualdade objetiva está posta, mas não a sua efetividade. Em todos os campos a evolução das mulheres é marcante, e resultante de uma história de lutas e muitas conquistas.

Os modelos tradicionais do Estado e a consequente configuração dos direitos fundamentais que os acompanha, encontram-se ultrapassados, pois incapazes de oferecer respostas idôneas às demandas da sociedade. Tanto o Estado Liberal, com as suas regras formais de direitos, quanto o Estado do Bem Estar Social, com a sua suposta materialização uniforme e burocrática, se mostram carentes em viabilizar o reconhecimento de grupos minoritários que se auto reconhecem por critérios de gênero, cor, raça, procedência nacional, orientação sexual e identidade de gênero, e que demandam reconhecimento de sua 
diversidade ou que, de toda sorte, são colocados em condição de inferioridade, e por isso, precisam que o Estado empreenda políticas especiais e específicas para promoção da igualdade.

O historicismo dos Direitos Humanos e o surgimento do movimento feminista coincidem. Contemporaneamente, a discriminação feminina no mercado de trabalho ainda é uma realidade que precisa ser vencida, não só no Brasil, mas mundialmente. Para identificação dos instrumentos que viabilizem os objetivos para o cumprimento das metas de 2030 das Organizações das Nações Unidas, se faz necessário um estudo dos direitos humanos internalizados pelo Estado brasileiro, emovimentos sociais, pela cultura e seus reflexos na sustentabilidade.

Para isso, o artigo faz uma análise da problemática da desigualdade de gênero sob a perspectiva dos antecedentes históricos das mulheres, os direitos humanos e o surgimento do feminismo, o Estado Democrático de Direito e o princípio da igualdade, os direitos humanos, os aspectos constitucionais da igualdade feminina na legislação infraconstitucional internalizados e estabelecidos no Brasil, o mercado de trabalho feminino, a cultura de gênero e seus reflexos no trabalho feminino, a sustentabilidade e as políticas públicas destinadasàs mulheres.

O presente artigo foi elaborado por meio de pesquisa bibliográfica e metodologia descritiva, com análises estatísticas fornecidas pelo Anuário de Mulheres de $2013^{1}$ e pelo Relatório Anual do Observatório Brasil da Igualdade de Gênero 2009/2010, que são coletâneas de pesquisas. São também utilizados dados das pesquisas "Mulheres Brasileiras e gênero nos espaços públicos privados" de 2010, por conter dados mais específicos sobre a discriminação verticalizada nas empresas.

\footnotetext{
1Disponível em: https://pt.slideshare.net/paula0814/anuario-dasmulheres. Acesso em: 08/08/2016
} 


\section{OS ANTECEDENTES HISTÓRICOS}

O marco dos Direitos Humanos no mundo é a Constituição Francesa de $1791^{2}$, cujo congraçamento consolidou com as dimensões de liberdade, igualdade e fraternidade e cuja redação excluiu as mulheres da condição de cidadãs.

Mary Wollstonecraft (2016, p. 10) publica em 1790, na Inglaterra, o documento "Reinvindicação dos Direitos da Mulher". Militante feminista, Wollstonecraft tinha como bandeira a causa dos oprimidos e da escravidão doméstica da mulher. Compartilhou com a francesa Olympe de Gouges (CASTRO, 2016, p. 187) em 1791, os mesmos ideais iluministas de que a mudança só viria por meio da educação e universalização dos direitos.

$\mathrm{Na}$ Inglaterra do século XVIII, o comum era a exclusão das mulheres da educação formal e, consequentemente, das universidades e do trabalho em espaço público, sendo sempre dependente do marido e impedida de trabalhar sem seu consentimento, concretizando assim a inferioridade de gênero.

Olympe de Gouges (CASTRO, 2016, p. 193) participou das agitações políticas produzindo panfletos, tratados políticos, peças de teatro e artigos sobre a condição feminina, envolvendo-se de forma intensa no período posterior à queda da Bastilha. Seu ativismo como proprietária do jornal "L'Impatient", espelhava seus ideais de igualdade e liberdade radicalmente, e este ativismo político ensejou sua morte trágica. Compreendia que na publicação da Declaração dos Direitos do Homem, claramente o "homem" não estava retratado como "humanidade", mas como o único a possuir o direito à cidadania, vindo o manifesto a fazer um contraponto com caráter inclusivo nos seguintes termos: "Mulher nasce livre e permanece igual ao homem em direitos" - Declaração dos Direitos da Mulher de 1.791 (WOLLSTONECRAFT, 2016, p. 10).

De forma mais ampla que Mary Wollstonecraft (2016), Olympe de Gouges (WOLLSTONECRAFT, 2016, p. 09) não se limitou à igualdade dos direitos da mulher, indo além, reivindica o direito à educação, ao voto, à propriedade privada, a cargos públicos, ao reconhecimento dos filhos fora do casamento, e à herança. A

${ }^{2}$ Disponível em: http://www.elysee.fr/la-presidence/la-declaration-des-droits-de-l-homme-et-ducitoyen/. Acesso em: 07 jul. 2018. 
diferença entre ambas reside na origem familiar de cada uma. Olympe morreu decapitada em razão de uma peça teatral em que criticava os desmandos da Revolução Francesa (WOLLSTONECRAFT,2016, p. 10).

No Brasil, os ecos destas duas fundadoras do movimento feminista, partiu de Dionísia Pinto Lisboa (1810-1885), conhecida publicamente como Nísia Floresta, reconhecida pelos historiadorescomo uma das primeiras feministas brasileiras (AGASSIZ, 1938, p. 102). Em viagens frequentes a França, conviveu e compartilhou ideais de igualdade com Auguste Comte (NÍSIA..., 2014), sociólogo e fundador do positivismo jurídico, e reconhecido como defensor da causa feminina.

Em 1832, Nísia Floresta publicou "Direitos das mulheres e injustiça dos homens", obra que a autora entendia como uma tradução de "Reivindicação dos Direitos da Mulher", mas que historiadores entendem como tradução de "Woman not Inferior to Man", de autoria desconhecida, publicada com o pseudônimo de Sofia, e que inaugura o feminismo no Brasil. Funda a Escola Augusto, em Porto Alegre, na qual era permitido às meninas, o contato com as disciplinas ensinadas em colégios masculinos, vez que, à época, a educação feminina era circunscrita as tais "prendas domésticas", e seus horizontes se atrelavam unicamente ao casamento (CAMPOI, 2011).

Mary Del Priori (2000, p. 9) assinala:

[...]O sistema patriarcal instalado no Brasil colonial, sistema que encontrou grande reforço da Igreja Católica, que via as mulheres como indivíduos submissos e inferiores, acabou por deixar-lhes, aparentemente, pouco espaço de ação explícita. Mas insisto: isso era apenas mera aparência, pois, tanto na sua vida familiar, quanto no mundo do trabalho, as mulheres souberam estabelecer formas de sociabilidade e de solidariedade que funcionavam, em diversas situações, como rede de conexões capazes de reforçar seu poder individual ou de grupo, pessoal ou comunitário. (DEL PRIORI, 2000, p. 9)

A diferença entre as feministas europeias e as brasileiras é que as brasileiras pertencem à classe social abastada, e à elite de mulheres emancipadas, cujas ideias, à época, não ecoavam na sociedade brasileira de cunho eminentemente patriarcal, e não foram suficientemente capazes de arregimentar seguidoras, tal o atraso cultural vivenciado no Brasil. 
Na Primeira República, tínhamos unicamente o voto dos homens com renda e alfabetizados, dispúnhamos de um único partido, e a escravidão praticamente adentrou pelo século XX. O vínculo entre as fundadoras do movimento feminista é a visão do feminismo como um movimento social, emergido junto de ideais de fraternidade, igualdade e liberdade, cuja defesa era de uma república laica e de cidadania para todos. Era a radicalização da democracia por meio do feminismo, como sujeito do próprio desejo e de superação financeira.

$\mathrm{O}$ ponto em comum dessas fundadoras do movimento feminista foi a emancipação das mulheres por meio do acesso à educação, e pela luta da inclusão feminina no espaço público, e asseveram a contemporaneidade do tema e do assunto.

\section{O ESTADO DEMOCRÁTICO DE DIREITO E A CONSOLIDAÇÃO DO PRINCÍPIO DA IGUALDADE}

A noção consagrada do Estado Democrático de Direito sintetiza dois conceitos: a democracia e o constitucionalismo. Luís Roberto Barroso (2015, p.113) explica que ambos são inconfundíveis:

[...] Constitucionalismo significa essência, limitação do poder e supremacia da lei (estado de direito, rule of law, Rechtsstaat). Democracia, por sua vez, em aproximação sumária, traduz-se em soberania popular e governo de maioria. Entre constitucionalismo e democracia podem surgir, eventualmente, pontos de tensão: a vontade da maioria pode ter de estancar diante de determinados conteúdos materiais, orgânicos ou processuais da Constituição. (BARROSO, 2015, p.113)

O estudo da igualdade foi iniciado na antiguidade clássica por Aristóteles (GOYARD-FABRE, 2006, p.15), que a vinculava com a ideia de justiça. Contemporaneamente, a igualdade e a não discriminação compõem o ideal democrático, definida por Canotilho (1998, p. 281) de forma objetiva como:

[...] é conhecida formulação de Lincoln quanto à essência da democracia: "governo do povo, pelo povo e para o povo". Ainda hoje se considera esta formulação como síntese lapidar dos momentos fundamentais do princípio democrático. Designamos aqui como a formula de Lincoln como um modo de justificação positiva da 
democracia. [...] O princípio democrático não se compadece com uma compreensão estática de democracia antes de mais, é um processo de continuidade transpessoal, irredutível a qualquer vinculação do processo político a determinadas pessoas. (CANOTILHO, 1998, p. 281)

Nesse passo, é importante como o conceito de cidadania aponta o vínculo entre o indivíduo e o Estado. Pacheco (apud SIQUEIRA JÚNIOR; OLIVEIRA, 2007, p. 238) define como "O status civitatis ou estado de cidadania implica uma situação subjetiva, esparzindo os direitos e deveres de caráter público das pessoas que se vinculam ao Estado. Estabelece-se um círculo de capacidade conferido pelo Estado aos cidadãos".

Conclui-se, então, que cidadania representa o exercício de um direito e possui um liame estreito com a democracia. Para Arendt (apud LAFER, 1988, p.146) "cidadania é a consciência que o indivíduo tem do direito a ter direitos".

Estão estabelecidos nos textos mais relevantes de Direitos Humanos: na Declaração Universal dos Direitos do Homem de 1948 - $\operatorname{artigos} 1^{\circ}$ e $2^{\circ}$, na Convenção sobre a eliminação de todas as formas de discriminação racial de 1965 , que determina que todos os Estados se obrigam a "proibir e eliminar a discriminação racial, sob todas as formas, e a garantir o direito de cada um à igualdade perante a lei sem distinção de raça, de cor ou de origem nacional ou étnica"3, nomeadamente no exercício "direito do trabalho",artigo 5, C, i, do mesmo diploma ${ }^{4}$, e à "livre escolha do trabalho"; no Pacto Internacional dos Direitos Civis e Políticos de 1966, no Pacto Internacional de Direitos Econômicos, Sociais e Culturais, também de 1966 na Convenção Sobre a Eliminação de Todas as Formas de Discriminação Contra as Mulheres ${ }^{5}$; neste, especificamente aprovado em 17 de Dezembro de 1979, pela Assembleia Geral das Nações Unidas se estabelece que os "Estados Partes condenam a discriminação contra as mulheres sob todas as suas

\footnotetext{
${ }^{3}$ Disponível em: http://legis.senado.gov.br/legislacao/ListaTextolntegral.action?id=94836. Acesso em: 22 abr. 2018.

${ }^{4}$ Disponível em: http://legis.senado.gov.br/legislacao/ListaTextolntegral.action?id=94836. Acesso em: 22 abr. 2018.

${ }^{5}$ Disponível em:

http://www.compromissoeatitude.org.br/wpcontent/uploads/2012/11/SPM2006_CEDAW_portugues.pdf. Acesso em: 22 abr. 2018.
} 
formas", e "acordam prosseguir, por todos os meios apropriados e sem demora, uma política tendente a eliminar a discriminação contra as mulheres".

Em diversas convenções da Organização Internacional do Trabalho (OIT), sobre o assunto específico do acesso ao emprego, destaca-se a Convenção 111 de 158, o qual se refere a Discriminação no Emprego ou Profissão, e a Convenção 156 de 1981, que se refere à Igualdade de Oportunidades e Tratamento para Trabalhadores de Ambos os Sexos, constata-se um liame entre igualdade e não discriminação, sendo apelidado de "Decent Work", que tem por objetivo:

[...] ensure that people can find work, which is essential to moving out of poverty; and that the work they fin is decent - in term of providing a living for a worker and his or her Family, to being carried out under reasonable conditions and above all to ensuring that worker's fundamental rights are respected. (SWEPSTON, 2005, p. 11)

E em tratados ou declarações de direitos de certos blocos regionais, tais como Tratado da União Europeia, na Carta de Direitos Fundamentais da União Europeiaque dispõe:

[...] A União funda-se nos valores do respeito pela dignidade humana, da liberdade, da democracia, da igualdade, do Estado de Direito e do respeito pelos direitos do Homem, incluindo todas as pessoas pertencentes a minorias. Estes valores são comuns aos Estados membros, numa sociedade caracterizada pelo pluralismo, a não discriminação, a tolerância, a justiça, a solidariedade e a igualdade entre homens e mulheres. (COMISSÃO EUROPEIA, 2018, p. 2)

Cumpre ressaltar que os Estados Unidos da América (EUA) exerceram importante papel na afirmação universal do princípio da igualdade, assim como também na afirmação jurídica. A Constituição Americana, datada de 1787, foi a primeira e é a mais duradoura Carta Constitucional, ela inseriu em seu texto direitos fundamentais, ainda que, à época, os EUAenfrentasse o problema da escravidão e seu comércio com os Estados do Sul. Entretanto, com a Declaração de Independência uma parcela considerável dos estados federados incluiu, em separado, declarações de direitos, e outros estados federados incorporaram tais princípios em seus respectivos textos, como direitos fundamentais de seus cidadãos. 
Neste contexto, a afirmação da igualdade se consolidara de forma irreversível. O Bill of Rights da Virginia ou The Virginia Declaration of Rights, é de autoria de George Mason $^{6}$, vindo a se tornar modelo nacional por ser o primeiro do gênero. Sobre o princípio da igualdade, o documento afirmava: "all men are by nature equally free and independent and have certain inherent rights".

A Constituição de Massachusetts, ou Constitution of the Commonwealth of Massachusetts, insculpiu a igualdade como: "All men born free and equal, and have a certain natural, essential, and unalienable rights", a qual foi adotada na "Déclaration des Droits de L'Homme et du Citoyen", sendo que, a partir de então, o princípio da igualdade passou a constar amplamente nas constituições dos estados americanos.

Nesse passo, partindo do raciocínio aristotélico (MARUANI; HIRATA, 2003, p.140), a igualdade vem sendo atrelada ao conceito de justiça, e como tal, como bem assinala Amartya Sen, a partir do sentido de justiça de Raws (SEN, 2012, p. 106)o qual reflete que todas as oportunidades necessitam estar abertas a todos "[...] sem que ninguém fique excluído ou tolhido, por exemplo, por motivo de raça, etnia, casta ou religião" [...] (SEN, 2012, p. 106).

Sob o ponto de vista rawlsiano, para Richard Arnenson (ARNENSON, 2008, p. 112), a igualdade é entendida como forma substantiva (substantive equality of opportunity), isto é, como faculdade atribuída a todos os cidadãos de terem acesso as mesmas oportunidades, com base nos respectivos méritos e talentos. Ora, está evidenciado que, no tocante a igualdade e não discriminação no acesso ao emprego, o alcance deste marco legislativo está fundado como uma prerrogativa de todos cidadãos no acesso às mesmas chances, baseados em mérito e talento.

O filósofo Stefan Gosepath entende a igualdade nos seguintes termos: "pelo menos desde a Revolução Francesa, a igualdade sempre serviu como um dos principais ideais da ação política" (GOSEPATH, 2011, p. 1), no sentido de que "o

\footnotetext{
${ }^{6}$ Disponível em: www.archives.gov/exhbits/charters/virginia_declaration_of_rights.html. Acesso em: 18 maio 2018.

${ }^{7}$ Disponível em: http://www.john-adams-heritage.com/text-of-the-masschusets-constitution/. Acesso em: 07 jul. 2018

${ }^{8}$ Disponível em: http://wwwelysee.fr/la-presidence/la-declaration-desdroits-de-l-Homme-et-du-citoyen. Acesso em: 07 jul. 2018
} 
princípio da igualdade, dignidade e respeito é hoje aceite como um minimum standard em toda a cultura ocidental." (GOSEPATH, 2011, p.8).

A relevância dos Estados Unidos para a afirmação do princípio da igualdade, e em especial para o acesso ao emprego e ao trabalho, foi e continua sendo decisivo nas Constituições dos Estados modernos. É relevante as diferenças nos sistemas da common law e os sistemas romano-germânico, o qual se insere o Brasil. No entanto, considerando as influências rawlsianas na substantive equality opportunity, que está fundamentada no critério de que todos os cidadãos devem ter acesso às mesmas oportunidades, com base no mérito e talento. No Brasil tanto o texto constitucional quanto a legislação internalizaram a igualdade de oportunidades no acesso ao trabalho e emprego, inclusive proporcionando as ações afirmativas.

Conforme o histórico apresentado nesta pesquisa, as mulheres alcançaram a cidadania tardiamente, sendo oportuno observar a transcendência dos efeitos negativos dessa admissão tardia ao universo de valores e direitos cívicos.

\section{A IGUALDADE FEMININA NA LEGISLAÇÃO INFRACONSTITUCIONAL}

Em análise objetiva, o sistema laboral brasileiro é caracterizado fundamentalmente por um conjunto de regras e princípios de não discriminação artigo $7^{\circ}$, XXX da Carta da República de $1988^{\circ}$.Adjetivada como "Constituição Cidadã", inaugurou uma nova ordem democrática, "tendo por fundamentos muito significativos de direitos, liberdades e garantias" (SARLET, 2012, p. 32), centra-se "na plena realização da cidadania, tem como fundamento o princípio da dignidade da pessoa humana"(SARLET, 2006, p. 47).

O artigo $1^{\circ}$ da Carta da República vigente expressa que a República Federativa do Brasil, como Estado Democrático, tem por princípios "a soberania, a cidadania, a dignidade da pessoa humana, os valores sociais do trabalho e da livre iniciativa e o pluralismo político" ${ }^{10}$, no art. $3^{\circ}$, parag. IV enumera como objetivos da

\footnotetext{
${ }^{9}$ Disponível em: http://www.planalto.gov.br/ccivil_03/constituicao/constituicaocompilado.htm. Acesso em: 24 abr. 2018

${ }^{10}$ Disponível

em: https://www.senado.leg.br/atividade/const/con1988/CON1988 05.10.1988/art 1 .asp. Acesso em: 26 abr. 2018.
} 
República promover o bem de todos, sem preconceitos de origem, raça, sexo, cor, idade e quaisquer outras formas de discriminação", associado ao artigo $5^{\circ}$ que determina que todos são iguais perante a lei, garantindo a brasileiros e estrangeiros a inviolabilidade do direito " à vida, à liberdade, à igualdade, à segurança e à propriedade". Paulo Bonavides orienta, no que tange à igualdade, que figura "entre os conceitos básicos da democracia. O princípio democrático sem igualdade não teria consistência". (BONAVIDES, 2001, p. 208).

$\mathrm{Na}$ Consolidação da Legislação Trabalhista (Decreto-Lei 5452 de 1 de Maio de 1943) artigos.372, 373-A, 391 e 393, 461 e 462, e Lei 9.029/95 ${ }^{11}$ (Lei 9.029 de 13 de Abril de 1995) - que trata da proibição do acesso ao emprego ou em sua permanência bem como a exigência de teste de gravidez na admissão, Lei $7.716 / 89^{12}$ (Lei 7.716 de 5 de Janeiro de 1989) proíbe a discriminação em geral raça, cor, etnicidade, religião ou origem nacional, Estatuto da Igualdade Racial - Lei $12.288 / 2010^{13}$ (Lei 12.288 de 20 de Julho de 2010), o qual elenca previsões políticas públicas para promoção de igualdade de oportunidades para a população negra. Lei $10.741 / 2003^{14}$ que proíbe a discriminação em razão da idade - mais de 60 (sessenta anos) no emprego, artigos 26, 27 e 28 Lei 7.783/99 que proíbe discriminação de trabalhadores sindicalizados ${ }^{15}$, art. 8 , VIII da Carta da República de $1988^{16}$, que proíbe discriminação contra sindicalização daqueles trabalhadores que sejam candidatos a lideranças sindicais ou líderes sindicais.

No que tange à igualdade, a legislação existente se refere à proibição de contratação das mulheres para trabalhar em atividades que exija grande esforço físico - artigos 198 e 390 da CLT.

O ordenamento jurídico pátrio firma o princípio da igualdade no âmbito formal, e no âmbito material proíbe a prática discriminatória e alberga as ações

\footnotetext{
${ }^{11}$ Disponível em: http://www.planalto.gov.br/ccivil_03/LEIS/L9029.HTM. Acesso em: 14 dez. 2018.

${ }^{12}$ Disponível em: http://www.planalto.gov.br/ccivil_03/LEIS/L7716.htm. Acessoem: 14 dez. 2018.

${ }^{13}$ Disponível em: http://www.planalto.gov.br/ccivil_03/_Ato2007-2010/2010/Lei/L12288.htm. Acesso em: 14 dez. 2018.

${ }^{14}$ Disponível em: http://www2.camara.leg.br/legin/fed/lei/2003/lei-10741-1-outubro-2003-497511publicacaooriginal-1-pl.html. Acesso em: 14 dez. 2018.

${ }^{15}$ Disponível em: http://www.planalto.gov.br/ccivil_03/decreto-lei/Del5452.htm. Acessoem: 28 abr. 2018.

${ }^{16}$ Disponível em: http://www.planalto.gov.br/ccivil_03/constituicao/constituicaocompilado.htm. Acesso em: 28 abr. 2018.
} 
positivas, em proteção a mulher. Contudo, a cultura arraigada de dominação masculina na sociedade ainda é uma barreira a ser transposta.

\section{O MERCADO DE TRABALHO FEMININO}

$\mathrm{Na}$ atualidade ainda constatamos, além das dificuldades econômicas estruturais, divergências salariais entre gêneros, que a sociedade ainda alega ser em razão da maternidade e da dupla jornada de trabalho.

A integração da mão de obra feminina no mercado de trabalho nas metrópoles foi intensificada entre os anos 1999 e 2009. Este é um dado demográfico recente. Ao nos depararmos com dados do IBGE referentes ao ano-base 2010, esbarramos com o seguinte: a renda feminina é quarenta por cento menor que a masculina com a mesma escolaridade na mesma atividade e no mesmo cargo.

De acordo com o IBGE(2012) considerando tratar-se da pesquisa mais recente nesta seara, osmaiores indicadores com maior população em nível médio e superior foram registrados pelas mulheres com ocupação entre os militares e funcionários públicos estatutários, 93,3\%, quando o perfil educacional dessas mulheres era de 11 anos. Outro ponto a observar é a participação das mulheres com 11 anos ou mais de estudo e com carteira assinada. Para elas, a participação foi de $77,5 \%$; enquanto para eles, esse indicador foi de $60,4 \%$ - uma diferença de 17,1 pontos percentuais em 2011.

No ano de 2003 essa diferença havia sido de 20,3 pontos percentuais. Dados do IBGE confirmam que a dimensão de homens em trabalhos domésticos com 11 anos ou mais de estudo era de $23,8 \%$, superior às mulheres com mesma escolaridade que ocupam esse trabalho, 19,2\%, indicando que, apesar de nesse trabalho a presença ser dominante entre as mulheres, a proporção de homens com pelo menos o ensino médio era maior que a das mulheres. É injustificável tal desigualdade, e tal constatação corrobora com o sistema patriarcal da sociedade brasileira.

Adicionado a este caldeirão de números, tem sido identificado outro problema pelos órgãos internacionais, o qual se encaixa perfeitamente ao problema brasileiro no que tange à ausência feminina em diversos campos do trabalho, bem 
como a ausência de promoção na mesma proporção que os homens, mesmo possuindo a mesma formação acadêmica e exercendo o mesmo cargo.

Paralelamente, temos ainda a questão da qualidade do emprego, onde o IBGE (2012) localiza que 68\% das mulheres exercem a atividade doméstica.

Existe uma necessidade premente de promoção da igualdade de gênero. Em pesquisa do Departamento Intersindidical de Estatística e Estudos Socioeconômicos (DIEESE) ${ }^{17}$ datada de março de 2013 , pesquisa efetuada sob efeito do recente e curto ápice econômico de 2010, aponta resultados positivos sobre as mulheres, onde houve registro de aumento de mulheres ocupadas nas maiores regiões metropolitanas, sendo essa taxa de ocupação maior que a masculina. Todavia, essa melhora não exclui a desigualdade na conjuntura de inserção ocupacional, com as mulheres permanecendo proporcionalmente menos ocupadas e sendo a maioria no rol dos desempregados, e com baixa qualidade de especialização no trabalho.

As pesquisas demonstram melhoria mínima em quantidade e qualidade de emprego, permanecendo a discriminação ampla e disseminada na sociedade brasileira.

\subsection{Aspectos da Cultura e Gênero: reflexos no trabalho feminino}

O filósofo e sociólogo Zygmunt Bauman conceitua a cultura em três vertentes: a cultura como conceito hierárquico, a cultura como conceito diferencial e o genérico, sintetizando-os com o seguinte raciocínio:

[...] Se a noção hierárquica de cultura coloca em evidência a oposição entre as formas de cultura "requintadas" e "grosseiras" assim como ponte educacional entre elas; se a noção diferencial de cultura é ao mesmo tempo um produto e um sustentáculo da preocupação comas oposições incontáveis e infinitamente multiplicáveis entre os modos de vida dos vários grupos humanos - a noção genérica é construída em torno da dicotomia mundo-humano e mundo-natura; ou melhor, da antiga e respeitável questão da filosofia europeia - distinção entre "actus hominis" ( o que acontece ao homem) e "actus humani" ( o que o homem faz). O conceito

\footnotetext{
${ }^{17}$ Disponível em:https://www.dieese.org.br/livro/2012/livroSituacaoTrabalhoBrasil.pdf. Acesso em: 14 jun. 2018.
} 
genérico tem a ver com os atributos que unem a espécie humana ao distingui-la dos demais. Em outras palavras, o conceito genérico de cultura tem a ver com fronteiras do homem e do humano. (BAUMAN, 2012, p. 102)

Partindo dessas considerações, percebemos que a cultura e o machismo se encontram totalmente imbricados na sociedade. Segundo a representante do Escritório da ONU Mulheres no Brasil, Nadine Gasman, apesquisasobre violência de gêneropesquisatrouxe "dados muito fortes" e reflete a estagnação da sociedade brasileira em questões de gênero e constata:

[...] é uma sociedade que ainda não acredita que mulheres e homens são iguais. "Essa questão é reveladora e temos que trabalhar muito para mudar as concepções de gênero. Temos que entender as construções sociais, de mulheres e homens, que são produtos de uma formação patriarcal, onde os homens têm vantagens que os colocam em uma situação de poder contra totalmente o que a humanidade dispõe de marco - de que nascemos livres e iguais" [...] (CRISTALDO, 2016).

O Instituto de Pesquisa Datafolha efetuou 3.625 entrevistas com pessoas a partir de 16 anos, em 217 municípios brasileiros, entre os dias $1^{\circ}$ e 5 de agosto de 2016. Este levantamento, considerou a definição de violência contra as mulheres dada pelas Nações Unidas, que é qualquer ato de violência de gênero que resulte ou possa resultar em dano físico, sexual, dano psicológico ou sofrimento para as mulheres, incluindo ameaças, coerção ou privação arbitrária de liberdade, tanto na vida pública como na vida privada. O levantamento indicou que $42 \%$ dos homens e $32 \%$ das mulheres entrevistados concordam com a afirmação: "mulheres que se dão ao respeito não são estupradas", enquanto apenas $63 \%$ das mulheres discordam. É o império da cultura machista sobre as mulheres também. Esse percentual deveria, em tese, beirar $100 \%$ (cem por cento).

Segundo a Organização Mundial de Saúde (OMS), a violência sexual é "qualquer ato sexual ou tentativa de obter ato sexual, investidas ou comentários sexuais indesejáveis ou tráfico ou qualquer outra forma, contra a sexualidade de uma pessoa usando coerção". A violência pode ser praticada por qualquer pessoa, independente da relação com a vítima, e em qualquer cenário, incluindo a casa e o trabalho. $\mathrm{O}$ ato pode acontecer em casa ou na rua. 
Dados do $9^{\circ}$ Anuário Brasileiro de Segurança Públicaapontam que foram registrados 47.646 casos de estupro em todo o país em 2014, o que significa um estupro a cada 11 minutos. Apesar do número de casos, a pesquisa destaca que a maioria das pessoas que sofre violência sexual não registra denúncia na polícia, o que torna difícil estimar a prevalência deste crime.

[...] Em termos regionais, o maior medo é verificado nas regiões Norte e Nordeste do país, atingindo $72 \%$ de toda a população. No entanto, se verificamos apenas as respostas das mulheres, notamos que $90 \%$ das mulheres que residem no Nordeste afirmam ter medo de sofrer violência sexual, seguidas de $87,5 \%$ da população feminina do Norte, $84 \%$ no Sudeste e Centro-Oeste e $78 \%$ no Sul do país", aponta o documento. (9 ${ }^{\circ}$ ANUÁRIO..., 2014).

O levantamento aborda a culpabilização pela violência sofrida pela mulher como uma reação frequentemente relatada, até mesmo quando elas recebem atendimento nos serviços de justiça, segurança e saúde.

[...] A dificuldade de reunir evidências materiais do não consentimento, bem como o risco de vitimização durante os procedimentos legais - humilhação, julgamento moral, procedimentos de coleta de provas que expõem o corpo violado da vítima a novas intervenções - são desafios específicos relacionados à violência sexual. (9 ANUÁRIO..., 2014).

Para a maioria das mulheres, o que se espera é que tenham, pelo menos, a oportunidade de desenvolver seus talentos, quaisquer que sejam. Para isso é fundamental que tenham condições de fazer o básico - estudar, trabalhar, votar, ter uma família. E que possam, caso queiram, disputar um cargo eletivo ou abrir um negócio.

Os números do Fórum Econômico Mundial mostram que esses direitos, não fazem parte da realidade de um grande número de mulheres. De acordo com o Relatório Global sobre Desigualdade de Gênero, divulgado em outubro de 2013, não há um país sequer onde as mulheres tenham as mesmas oportunidades que os homens nas áreas de educação, política, economia e saúde.

No Brasil, $65 \%$ das mulheres fazem a força de trabalho, ante $85 \%$ dos homens. Em média as mulheres ganham $61 \%$ dos salários dos homens. Apenas 
$18 \%$ das grandes empresas têm mulheres entre seus executivos. Elas ocupam apenas $9 \%$ das cadeiras do Congresso Nacional.

A relação entre educação, cultura, machismo, violência, é identificada como o principal entrave para inserção e manutenção das mulheres no mercado de trabalho, sendo certo que se refere à educação, devemos apontar que os homens são educados principalmente por mulheres.

$\mathrm{O}$ ano de 2015 foi decisivo para a igualdade e empoderamento das mulheres em razão do vigésimo aniversário da Declaração de Pequim e Plataforma de Ações das Organizações das Nações Unidas ${ }^{18}$ (ONU) e da Resolução 1325 do Conselho de Segurança sobre as Mulheres, Paz e Segurança. Esta plataforma, trata da Agenda 2030 para Eliminação da Desigualdade e o Desenvolvimento Sustentável, sendo o poder transformador feminino, como âmagopara os próximos quinze anos.

A persecução dos dezessete objetivos de Desenvolvimento sustentável, acrescentados a Meta 5 em particular, foi apoiado por 93 (noventa e três) países, assumindo compromissos concretos que visem crucialmente o desenvolvimento sustentável, estabelecendo uma data limite para a eliminação dos obstáculos estruturais à igualdade de gênero através de novos instrumentos, como por exemplo, apoio a uma maior participação das mulheres na força de trabalho e aumento de sua produtividade.

Estamos no segundo ano desta agenda mundial. O Brasil se encontra ainda distante na implementação de programas que visem remover as barreiras estruturais da igualdade de gênero e empoderamento das mulheres.

\section{MERCADO DE TRABALHO DA MULHER E SUSTENTABILIDADE}

A discussão acerca da sustentabilidade, no conceito vindo do direito ambiental, prima facie, afigura um pouco deslocado ao tratarmos do mercado de trabalho da mulher. As ideologias socialistas e liberais que, segundo Leite e Ayala (2010, p. 24) vez que desconsiderou a agenda ambiental nos respectivos projetos político-econômicos, em termos ambientais, promoveram crise ambiental sem

\footnotetext{
${ }^{18}$ Disponível em:http://www.onumulheres.org.br/pequim20/. Acesso em: 20 ago. 2016.
} 
precedentes no mundo. Vindo então ante a escassez de alguns recursos naturais, e o petróleo na década de 70 é o maior exemplo, foi desenvolvido o conceito de desenvolvimento sustentável à partir da Comissão Mundial do Meio-Ambiente e Desenvolvimento das Nações Unidas, que produziu o "Relatório Nosso Futuro Comum"19 de 1987, definiu a noção de desenvolvimento sustentável da seguinte forma: "...aquele que atende às necessidades do presente sem comprometer a possibilidade de as gerações futuras atenderem suas próprias necessidades."

Sarlet conceitua:

[...] A ideia de sustentabilidade encontra-se, portanto, vinculada, à proteção do ambiente, já que manter (e, em alguns casos, recuperar) o equilíbrio ambiental implica no uso racional e harmônico dos recursos naturais, de modo a por meio de sua degradação também não os levar ao seu esgotamento. (SARLET, 2012, p. 90).

O Brasil é signatário da Declaração sobre o Direito ao Desenvolvimento datada de 1986, que estabelece:

[...] o direito ao desenvolvimento é um direito humano inalienável, em virtude do qual toda pessoa e todos os povos estão habilitados a participar do desenvolvimento econômico, social cultural e político, a ele contribuir e dele desfrutar, no qual todos os direitos humanos e liberdades fundamentais possam ser plenamente realizados. (ONU, 1986).

O desenvolvimento pode ser conceituado como um processo de expansão das liberdades reais humanas, - as políticas, as econômicas, as sociais - a saber: saúde educação, incentivo e estímulo às iniciativas, isto é, "as diretrizes para o Desenvolvimento Econômico, como objetivo nacional, delimitado por meio de princípios fundamentais como forma de se alcançar à ordem econômica.". (BENFATI, 2014, p.152).

Posto isto, os dados do Fórum Econômico Mundial ${ }^{20}$ indicam que as nações com maior nível de igualdade de gêneros tendem a ser mais prósperas. Ou seja, dar às mulheres as mesmas oportunidades dos homens não é somente uma questão de

\footnotetext{
${ }^{19}$ Disponível em:http://www.onu.org.br/rio20/documentos/. Acesso em: 1 ago. 2018.

${ }^{20}$ Disponível em:observador.pt/2016/10/26/sao-precisos-170-anos-para-atingir-igualdade-de-generoeconomica/ Acesso em: 18 abr. 2018
} 
justiça - faz todo o sentido para a economia e sustentabilidade. Afinal, elas representam a metade da população mundial e somente $40 \%$ da força de trabalho. Apesar das barreiras de acesso à educação no Brasil e em vários países, as mulheres já são maioria nos cursos superiores.

Com base em uma amostra de mais de 60 países, pesquisadores do Fundo Monetário Internacional - FMl, estudaram alguns fatores considerados relevantes para um país ampliar a produtividade. Concluíram que as economias com maior participação das mulheres no mercado de trabalho são aquelas em que a produtividade cresce mais. Com a observância de que a presença feminina na força de trabalho está tão correlacionada aos ganhos de produtividade quanto ao fluxo de investimento direto, estrangeiro ou não.

Mame Astou Diouf ${ }^{21}$, uma das autoras da pesquisa mencionada, afirma: "Onde não há oportunidades iguais para homens e mulheres, também não há alocação eficiente de recursos humanos. Potencialmente, deixa-se de aproveitar algumas mentes brilhantes".

Constata este estudo que as mulheres, em geral, gastam a maior parte de sua renda com a família, diferentemente dos homens, que destinam boa parte do salário a outras despesas. Isto é, pagar um bom salário às mulheres é o mesmo que investir, - indiretamente - na educação e na saúde de gerações inteiras de crianças que, potencialmente, se tornarão adultos mais bem preparados para vida profissional.

O Fórum Econômico Mundial ${ }^{22}$ aponta que, apesar de um avanço quantitativo, existe uma falta de qualidade no trabalho feminino no Brasil. Quase 1/5 das brasileiras que trabalham são empregadas domésticas, o que confirma a pesquisa do IBGE.

A predominância de empregos pouco valorizados explica, em parte, as diferenças de remuneração entre homens e mulheres, muito embora não esclareça ou justifique totalmente a questão. Em média, as brasileiras recebem por hora trabalhada o equivalente a $84 \%$ do que os homens ganham. Verifica-se que essa

\footnotetext{
${ }^{21}$ Disponível em: observador.pt/2016/10/26/sao-precisos-170-anos-para-atingir-igualdade-de-generoeconomica/. Acesso em: 18 abr. 2018.

${ }^{22}$ Disponível em: observador.pt/2016/10/26/sao-precisos-170-anos-para-atingir-igualdade-de-generoeconomica/. Acesso em: 18 abr. 2018.
} 
distância aumenta na proporção em que aumenta o nível educacional: as mulheres que estudaram 12 anos ou mais recebem salários equivalentes a $66 \%$ dos homens com a mesma escolaridade. Provável tratar-se de um limite velado de ascensão profissional imposto às mulheres em razão dos potenciais "inconvenientes" que podem causar a seus empregadores, como o afastamento do trabalho por causa da maternidade.

Por outro vértice, temos ainda a questão da ocupação informal entre homens e mulheres que, possuindo uma altíssima taxa de emprego como domésticas, estasacabam sofrendo o fenômeno da informalidade de forma mais acirrada.

O empoderamento feminino no Brasil é o caminho para viabilizar a elaboração de propostas a serem implementadas pela sociedade civil, buscando dessa forma um desenvolvimento sustentável por meio da implementação de infraestrutura básica, para ajudar as mães que trabalham fora, e estimular as empresas a estabelecer uma meta, de ter pelo menos uma mulher em seu corpo de executivos, o que só ocorre em ínfima minoria das companhias, não só da economia regional, mas de todo o País, sendo certo que o Brasil assumiu, não só a persecução dos dezessete objetivos da ONU, mas de forma particular, a META 5 $(\text { cinco })^{23}$. Ao par do compromisso de alcance das metas, torna-se urgente a viabilização das mesmas, com investimento na infraestrutura educacional básica, média, que possibilite às mulheres se dedicarem ao trabalho.

Países como a Noruega e o Japão adotaram mecanismos de incentivo fiscal para famílias lideradas por mulheres e instrumentos que penalizem a discriminação salarial. O Brasil já adota mecanismo semelhante, entretanto, se mostrou entre nós insuficiente, ou pouco operante em razão da ausência de fiscalização governamental neste sentido.

É de extrema importância a ampliação e o impacto da educação das crianças, e principalmente das meninas. O ex-ministro de Desenvolvimento dos Recursos Humanos da Índia Sashi Tharoor, relaciona a educação das meninas como condição sine qua non para o desenvolvimento sustentável, e assevera que "estudos científicos e pesquisas determinaram algo que o senso comum talvez já

${ }^{23}$ Disponível em: http://www.onumulheres.org.br/referencias/legislacao-e-convencoes/. Acesso em: 04 abr. 2018. 
nos tenha dito: ao educar um menino você educa uma pessoa; ao educar uma menina, você educa uma família e beneficia uma comunidade inteira" (THAROOR, 2013, p.101).

A Unesco desenvolveu um projeto onde está demonstrado que "cada ano adicional de educação de uma mãe diminuía a taxa de mortalidade infantil de $5 \%$ a $10 \%$, demonstrando e confirmando a educação como tecnologia e instrumento de cidadania.

A necessidade do aumento da escolaridade das mulheres e mães tem um impacto mensurável na saúde e educação de seus filhos, bem como na produtividade quando chegam na fase adulta. Isso é tão importante que um estudo da Universidade de Yale constatou que o peso do recém-nascido de mães que possuem educação básica é consistentemente mais elevado do que o dos bebês de mães sem escolaridade.

\section{NOTAS FINAIS}

O paradigma do Estado Democrático de Direito, então, se coloca como possível resposta às dificuldades não solucionadas pelos anteriores, já que toma a diversidade e a crise como componentes normais da democracia, podendo oferecer resposta aos atuais problemas de fragmentação social, multiplicidade, vez que trabalha com a inquietude da democracia (vontade da maioria) e constitucionalismo (proteção às minorias), fundamental para conscientização do papel do Direito e dos Poderes Públicos na atualidade.

O caminho para o alcance da cidadania plena pelas mulheres é longo, Mill (MILL, 1911, p.33) afirma "que as mulheres não são treinadas apenas para servir aos homens (maridos, pais, irmãos mais velhos, sogros, cunhados); são treinadas para desejarem servi-los.", alicerçada em constatação tão antiga e simultaneamente tão atual, a subordinação feminina é diferenciada em relação a outros indivíduos e grupos, e a educação feminina não está direcionada para a formação de cidadãs democráticas, se pautando, ainda, para a vida doméstica, independente da classe social, sendo culturalmente valorizadas as virtudes ligadas ao espaço privado. Tais componentes sociais corroboram inúmeras modalidades de exclusão do espaço 
público, ocasionando o desinteresse e a exclusão no plano político democrático, acarretando a dominação cultural e econômica.

Percebe-se que, num mundo tão materialista, o empoderamento feminino poderá não só reverter, mas construir um respeito aos iguais, mesmo sendo essencialmente desiguais.

\section{REFERÊNCIAS}

$9^{\circ}$ ANUÁRIO Brasileiro de Segurança Pública. Disponível em:

http://www.forumseguranca.org.br/publicacoes/9o-anuario-brasileiro-de-segurancapublica/ Acesso em: 04 maio 2018.

AGASSIZ, Luiz, AGASSIZ, Elizabeth Cary. Viagem ao Brasil: 18651866.Companhia das Letras, 1938.

ANUÁRIO das mulheres. Disponível em: https://pt.slideshare.net/paula0814/anuario-dasmulheres. Acesso em: 08 mar. 2018.

ANUÁRIO das mulheres.Disponível em:

http://www.forumseguranca.org.br/publicacoes/9o-anuario-brasileiro-de-segurancapublical. Acesso em: 08 mar. 2018.

ARNENSON, Richard. Equality Law after Opportunity. The Stanford Encyclopedia of Philosophy, Eduard Zalta editor, Fall Edition, 2008.

BARROSO, Luís Roberto. Curso de Direito Constitucional contemporâneo. São Paulo, Editora Saraiva, 5. ed. 2015.

BAUMAN, Sigmund. Ensaios sobre o Conceito de Cultura. Rio de Janeiro: Editora Zahar, 2012.

BENFATI, Fábio Fernandes Neves. Direito ao Desenvolvimento. São Paulo, Editora Saraiva, 2014.

BONAVIDES, Paulo. O Princípio da Igualdade como limitação à atuação do Estado. Revista de Direito Constitucional, Igualde e Justiça, 2003.

NÍSIA Floresta, a primeira feminista brasileira. In: Blogueiras Feministas. [S.I.], 06 ago. 2014. Disponível em: http://blogueirasfeministas.com/2014/08/nisia-floresta-aprimeira-feminista-brasileira. Acesso em:14 dez. 2018.

CAMPOI, Isabela CandeloroO livro "Direitos das mulheres e injustiça dos homens" de Nísia Floresta: literatura, mulheres e o Brasil do século XIX. História (São Paulo), São Paulo, v.30, n.2, dez. 2011. Disponível 
em:http://www.scielo.br/scielo.php?pid=S0101-

90742011000200010\&script=sci_arttext, http://dx.doi.org/10.1590/S0101-9̄0742011000200010. Acesso em: 14 dez. 2018.

CANOTILHO, Joaquim Gomes, José. Direito constitucional e teoria da constituição. 3. ed. São Paulo: Livraria Almedina, 1998.

CASTRO, Flávia Lages de. História do Direito Geral e do Brasil. 5. ed. São Paulo. Editora Lúmen Juris, 2007.

COMISSÃO EUROPEIA. Proposta de regulamento do parlamento europeu e do conselho que cria o programa «Direitos e Valores». Bruxelas, 2018. Disponível em: https://eur-lex.europa.eu/resource.html?uri=cellar:41417a42-6af2-11e8-948301aa75ed71a1.0021.02/DOC_1\&format=PDF. Acesso em: 14 dez. 2018.

CRISTALDO, Heloisa. ONU Mulheres: Brasil diz que pesquisa sobre estupro reflete a sociedade. Agência Brasil, Brasília, 24 set. 2016. Disponível em:

http://agenciabrasil.ebc.com.br/geral/noticia/2016-09/onu-mulheres-brasil-diz-quepesquisa-sobre-estupro-reflete-estagnacao-da. Acesso em: 10 dez. 2018.

DEL PRIORI, Mary. Mulheres do Brasil Colonial. São Paulo. Editora Contexto, 2000.

IBGE. Mulher no mercado de trabalho: perguntas e respostas. 2012. Disponível em:https://www.ibge.gov.br/home/estatistica/indicadores/trabalhoerendimento/pme_n ova/Mulher_Mercado_Trabalho_Perg_Resp_2012.pdf. Acesso em: 14 dez. 2018.

MARUANI, Margaret; HIRATA, Helena (Org.). As novas fronteiras da desigualdade: homens e mulheres no mercado de trabalho. São Paulo: Senac, 2003.

ONU. Declaração sobre o Direito ao Desenvolvimento: 1986. 1986. Disponível em: http://www.direitoshumanos.usp.br/index.php/Direito-ao-

Desenvolvimento/declaracao-sobre-o-direito-ao-desenvolvimento.html. Acesso em: 14 dez. 2018.

GOSEPATH, Stefan. Equality. The Stanford Encyclopedia of Philosophy, spring, 2011 edition.Eduard N. Zalta Editor.

GOYARD-FABRE, Simone. Filosofia Crítica e razão jurídica. Trad. Maria Ermantina de Almeida Prado Galvão. [S.I.]: Ed. Martins Fontes, 2006.

LAFER, Celso. A reconstrução dos direitos Humanos: um diálogo com o pensamento de Hannah Arendt. São Paulo. Companhia das Letras, 1988.

MILL, John Stuart. The Subjection of Women. Oxford: Oxford University Press, 1911. 
LEITE, José Rubens Morato; AYALA, Patryck de Araújo. Dano Ambiental: do individual ao coletivo extrapatrimonial (teoria e prática). São Paulo: Revista dos Tribunais, 2010.

SARLET, Ingo Wolfgang. A eficácia dos direitos fundamentais: uma teoria dos direitos fundamentais numa perspectiva constitucional. 11. ed. Porto Alegre: Livraria do Advogado, 2012.

SARLET. Dignidade da Pessoa Humana e Direitos Fundamentais. Porto Alegre, Livraria do Advogado, 2006.

SEN, Amartya. A ideia de Justiça. Coimbra: EdiçõesAlmedina, 2012.

SIQUEIRA JÚNIOR, Paulo Hamilton; OLIVEIRA, Miguel Augusto Machado de.

DireitosHumanos e Cidadania. São Paulo: Revista dos Tribunais, 2007.

SWEPSTON, Lee. ILO Standards and Globalization. Bulletin of Comparative Labor Relations, Wolters Kluwer Law and Business, Netherlands, n. 55, 2005.

THAROOR, Shashi. PaxIndica: India and the World of the $21^{\circ}$ Century. New Delhi: Penguin Books, 2013.

WOLLSTONECRAFT, Mary. Reivindicação dos direitos da mulher. Trad. de Ivania Pocinho Motta. São Paulo: Boitempo, 2016. 